\title{
Resistência à compressão e viabilidade econômica de blocos de concreto dosado com resíduos de tijolos cerâmicos
}

\section{Compressive strength and economic viability of concrete blocks with ceramic brick residues}

\footnotetext{
${ }^{1}$ Faculdade de Engenharia Agrícola - Universidade Estadual de Campinas - FEAGRI/UNICAMP, CEP: 13083-875, Campinas, SP, Brasil.

e-mail: micaelfelipe@gmail.com; julio.soriano@feagri.unicamp.br; marco.ospina@ feagri.unicamp.br
}

\section{RESUMO}

Os tijolos e blocos cerâmicos são empregados em larga escala nas construções das alvenarias de vedação ou estruturais, proporcionando condições adequadas de conforto ao ambiente interno. Na fabricação desses elementos cerâmicos há necessidade de se excluir as peças com defeitos, originados da não conformidade das dimensões, das falhas no processo de queima ou quebras. O simples descarte dessas peças com defeito em aterros gera custos de remoção e impactos ambientais, bem como o desperdício de um material que contém suas propriedades físicas e mecânicas inerentes. Nesse contexto, o presente trabalho teve como objetivo avaliar, sob os aspectos da resistência à compressão e econômicos, a viabilidade do emprego de agregados oriundos do resíduo de tijolos cerâmicos na dosagem de concreto para produção de blocos maciços para pavimentação e para alvenaria. Para tanto, foram triturados tijolos cerâmicos, em moinho de martelos e elaboradas misturas de concreto com substituição dos agregados (miúdo e graúdo). O desempenho mecânico dos blocos produzidos foi avaliado por ensaio à compressão simples e a viabilidade econômica para implantação do processo de aproveitamento dos resíduos foi analisada para cenários com um horizonte de cinco anos, utilizando o fluxo de caixa para calcular o retorno do investimento inicial. Os resultados mostraram que os blocos produzidos com a substituição de $80 \%$ do agregado miúdo apresentaram um elevado desempenho mecânico e comprovada viabilidade econômica. Com base nestes resultados, conclui-se que a produção de blocos para pavimentação e alvenaria é uma solução viável para o aproveitamento e destino dos resíduos da indústria cerâmica.

Palavras-chave: agregados cerâmicos; descarte de olaria; aproveitamento de resíduos; fluxo de caixa; plano de produção.

\begin{abstract}
Bricks and ceramic blocks are widely used in constructions of structural and non-structural masonry, providing adequate conditions of comfort to the indoor environment. The manufacture of these ceramic products implies discarding of damaged elements, due to non-conformity of dimensions, failures in the process of burning or breaking. The simple disposal of these pieces in landfills generates removal costs and environmental impacts, as well as the waste of material that still contains valuable physical and mechanical properties. In this context, the objective of the present work was to evaluate the viability of using aggregates from the ceramic brick residue in the concrete dosage to produce solid blocks for paving and masonry, concerning their compressive strength and the economics aspects. For this purpose, ceramic bricks were grounded in hammer mills to elaborate concrete mixtures with replacement of aggregates (fine and coarse). The mechanical performance of these blocks was evaluated by using a compression test as well as the economic feasibility of the waste recovery process in a five-year horizon for different scenarios. The results indicate that blocks produced with substitution of $80 \%$ of fine aggregate presented a high mechanical performance and economic
\end{abstract}


viability. It is concluded that production of blocks for paving and masonry is a viable solution for the recovery and destination of waste from the ceramic industry.

Key words: ceramic aggregates; discard of pottery industry; waste recovery; cash flow; production plan.

\section{INTRODUÇÃO}

Os tijolos cerâmicos vêm sendo utilizados desde a antiguidade por ser um material fundamental na construção civil, dado que a sua principal matéria prima (argila) é proveniente da natureza e com grande disponibilidade. Os processos de fabricação das peças proporcionam resistência aos carregamentos usuais de construção e às tensões devidas às condições de exposição ambiental [1,2]. No entanto, segundo OLIVEIRA [3], as peças cerâmicas com defeitos, tais como por queima inadequada, cor desuniforme, trincas e quebras, dada a incompatibilidade para a comercialização, necessitam ser descartadas pelas indústrias fabricantes.

Os descartes de tijolos e blocos cerâmicos quando realizados de forma incorreta, com o simples depósito na natureza podem gerar graves impactos ambientais, sociais e econômicos. Com o propósito de se evitar o acúmulo de resíduos diversos no meio ambiente, há uma tendência mundial de utilização de agregados reciclados para produção de artefatos de cimento, propiciando, assim, o desenvolvimento sustentável $[4,5]$. Segundo HOOD [6], a reciclagem também pode promover outros benefícios, dentre eles a redução no consumo de recursos naturais não renováveis.

No caso da utilização de resíduos de tijolos e de blocos cerâmicos substituindo os agregados convencionais do concreto, as propriedades físicas e mecânicas resultantes da composição do traço são influenciadas pelos tipos das peças das quais se derivam os agregados [7,8]. O concreto elaborado com agregados cerâmicos reciclados pode ser utilizado na produção de peças pré-fabricadas destinadas às construções de alvenarias, bem como em outras aplicações como é caso de blocos fabricados para pavimentação [6,7].

Os blocos de concreto comumente produzidos para pavimentação (comercialmente denominados de pavers), de acordo com a ABNT NBR 9781:2013 [9], são elementos básicos maciços com formatos geométricos regulares que permitem o intertravamento. $\mathrm{O}$ crescente e generalizado uso da pavimentação, associado à necessidade de redução no consumo de recursos naturais e dos custos de produção, tem estimulado pesquisas que objetivam incorporar diferentes resíduos na elaboração de concretos alternativos para produção de blocos para pavimentação [10, 11]. As pesquisas desenvolvidas por POON e CHAN [7], RODRÍGUEZ et al. [5] e SILVA et al. [12], sob aspectos das propriedades mecânicas e físicas, confirmam a possibilidade da utilização de resíduos de tijolos cerâmicos como agregados reciclados na fabricação de blocos para pavimentação. No entanto, a maioria desses estudos não abordam a viabilidade econômica da utilização dos materiais alternativos, como é o caso dos agregados cerâmicos.

As empresas da construção civil têm o interesse em investir em novas tecnologias para reaproveitamento de resíduos. Entretanto, alguns aspectos devem ser considerados, como o alto valor de investimento e o retorno financeiro. Dessa forma, fica evidente a importância de análises econômicas. A viabilidade econômica de um projeto baseia-se em verificar se as receitas inerentes ao projeto superam os custos e os investimentos necessários para colocá-lo em prática [13]. Segundo BAUMGÄRTNER e QUASS [14], a viabilidade deve ser um critério normativo para qualquer sistema econômico-ecológico. O projeto é considerado viável quando o investimento oferece retornos maiores que seus custos, aumentando o lucro da empresa [15].

O objetivo deste trabalho foi avaliar se é viável o emprego de agregados reciclados oriundos do descarte de tijolos cerâmicos na dosagem de concreto para produção de blocos maciços para pavimentação e alvenaria. A análise da viabilidade fundamentou-se no aspecto da resistência à compressão e na estimativa dos custos para implantação de uma unidade de fabricação desses blocos não convencionais.

\section{MATERIAIS E MÉTODOS}

$\mathrm{Na}$ fabricação de peças de concreto para pavimentação ('pavers'), um requisito importante para as peças prémoldadas destinadas ao tráfego de pedestres, veículos leves e veículos comerciais de linha (sem abrasão acentuada) é a resistência característica à compressão $\left(\mathrm{f}_{\mathrm{pk}}\right)$, que deve ser igual ou superior a $35 \mathrm{MPa}$, conforme ABNT NBR 9781:2013 [9]. O processo de produção denominado 'dormido' requer um baixo investimento, sendo viável principalmente para pequenos fabricantes que investem em fôrmas plásticas ou metálicas e numa mesa vibratória.

No desenvolvimento desta pesquisa foram produzidos três grupos de blocos de concreto maciços, medindo $100 \mathrm{~mm}$ x $200 \mathrm{~mm}$ x $60 \mathrm{~mm}$, com traços de concreto modificados pela substituição dos agregados convencionais por agregados cerâmicos produzidos da reciclagem de tijolos cerâmicos descartados no processo de produção, por quebra ou empenamento. Como agregados convencionais foram empregadas a pedra britada 0 (com diâmetro máximo de $9,5 \mathrm{~mm}$ ) e areia média lavada (partículas passantes pela peneira com 
abertura de malha de 4,75 $\mathrm{mm}$ e retidos na peneira com abertura de 0,15 mm). Os agregados cerâmicos foram obtidos por moagem e peneiramento de tijolos descartados pela empresa oleira L. C. de Camargo (Rio Claro, SP, Brasil). Os traços foram elaborados com cimento Portland CPV-ARI sem adições.

Foram selecionados oito (8) tijolos cerâmicos maciços sem defeitos e com dimensões de $100 \mathrm{~mm} \mathrm{x}$ $200 \mathrm{~mm}$ x $50 \mathrm{~mm}$, os quais foram produzidos pela mesma olaria L. C. de Camargo. Esses tijolos destinaramse ao ensaio de compressão de acordo com a ABNT NBR 15270-2:2017 [16] e, cujos resultados foram comparados com aqueles obtidos nos ensaios dos blocos moldados com concretos dosados com resíduos cerâmicos em substituição aos agregados convencionais.

\subsection{Produção dos agregados cerâmicos}

Os agregados cerâmicos oriundos de tijolos descartados pela presença de defeitos foram produzidos pelo processo de moagem num moinho de martelos (Furlan modelo MM, Manchester). O resíduo de tijolo cerâmico moído (RTM) foi submetido ao processo de peneiramento, buscando-se então obter o agregado cerâmico graúdo RTM¹, Figura 1A (material passante pela peneira de malha 9,52 mm e retido na peneira de malha 4,75 $\mathrm{mm}$ ) e o agregado cerâmico miúdo RTM², Figura 1B (partículas passantes na peneira de malha 4,75 mm).
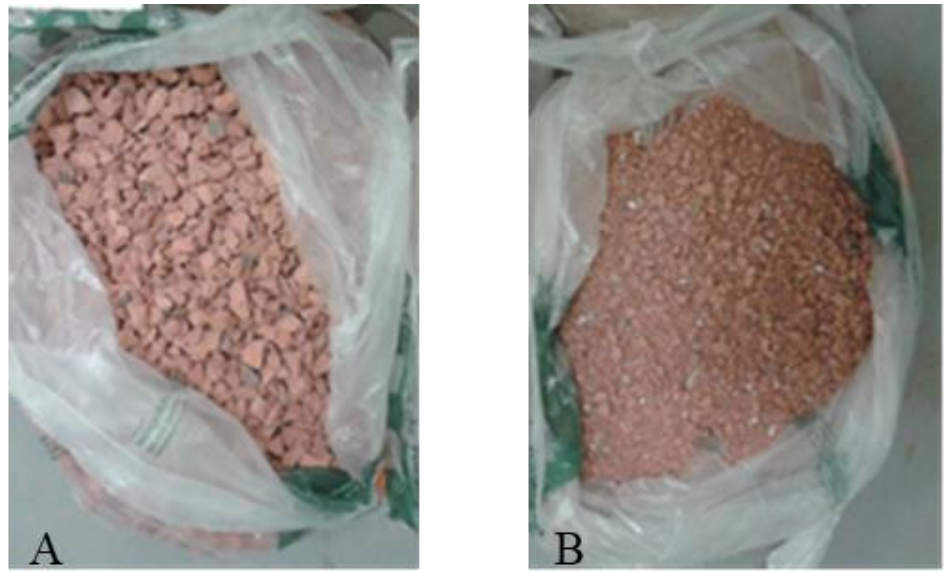

Figura 1: Agregados reciclados produzidos por moagem e peneiramento do resíduo de tijolo cerâmico. A) agregado graúdo $\left.\left(\mathrm{RTM}^{1}\right) ; \mathrm{B}\right)$ agregado miúdo $\left(\mathrm{RTM}^{2}\right)$.

O material que no primeiro peneiramento ficou retido na peneira de malha $9,52 \mathrm{~mm}$ foi ressubmetido às sucessivas triturações e peneiramento. Esse procedimento de caracterização garantiu que todo o material cerâmico triturado se enquadrasse nas granulometrias do $\mathrm{RTM}^{1}$ ou $\mathrm{RTM}^{2}$.

\subsection{Blocos com agregados cerâmicos}

O estudo inicial para a definição de um traço de referência desta pesquisa considerou o traço elaborado por POON e CHAN [7], no qual os autores empregaram agregados oriundos da reciclagem do concreto, na proporção em massa de $25 \%$ de agregado graúdo $(10 \mathrm{~mm})$ e $75 \%$ de agregado miúdo $(<5 \mathrm{~mm})$, tendo na composição do traço a relação 1:4,8 (cimento : agregados).

Buscando-se uma melhor trabalhabilidade da mistura e o melhor acabamento dos blocos, essa composição inicial passou por ajustes resultando na relação 1:5 (cimento : agregados) para constituir o traço de referência T0, em massa, 1:3:2:0,8 (cimento : areia : brita 0 : água/cimento), do qual derivaram os três traços com substituições dos agregados convencionais por agregados cerâmicos (oriundos da reciclagem dos tijolos cerâmicos) (Tabela 1). No traço denominado T1, 80\% do agregado miúdo (areia) foi substituído por agregado cerâmico de granulometria equivalente $\left(\mathrm{RTM}^{2}\right)$. No traço denominado T2, $80 \%$ das massas dos agregados convencionais (graúdo e miúdo) foram substituídas por agregados cerâmicos de granulometrias correspondentes (RTM1 e RTM²). Num terceiro traço (T3), 100\% da massa de agregado miúdo natural foi substituída por agregado cerâmico miúdo $\left(\mathrm{RTM}^{2}\right)$. Esses três traços elaborados contemplaram o uso de todo o material resultante da trituração, quer na substituição parcial da areia (T1), quer na substituição total da areia (T3) ou, ainda, nas substituições parciais da areia e da brita (T2). Na escolha dos traços elaborados com agregados reciclados de cerâmica, CABRAL et al. [17] concluíram que a substituição do agregado miúdo natural por agregado miúdo reciclado implica num aumento da resistência à compressão. Por outro, relatam que a substituição do agregado graúdo natural por agregado graúdo reciclado resulta no decréscimo dessa propriedade mecânica. 
Tabela 1: Composição dos traços de concreto em massa (kg).

\begin{tabular}{|c|c|c|c|c|c|c|}
\hline \multirow{2}{*}{ TRAÇO } & \multirow{2}{*}{ CIMENTO } & \multicolumn{2}{|c|}{ AGREGADO GRAÚDO } & \multicolumn{2}{|c|}{ AGREGADO MIÚDO } & \multirow{2}{*}{ ÁGUA } \\
\hline & & BRITA 0 & RTM $^{1}$ & AREIA & RTM $^{2}$ & \\
\hline TO & 1,0 & 2,0 & - & 3,0 & - & 0,8 \\
\hline T1 & 1,0 & 2,0 & - & 0,6 & 2,4 & 0,8 \\
\hline T2 & 1,0 & 0,6 & 1,6 & 0,6 & 2,4 & 0,8 \\
\hline T3 & 1,0 & 2,0 & - & - & 3,0 & 0,8 \\
\hline
\end{tabular}

Os componentes de cada um dos traços foram homogeneizados mecanicamente numa betoneira, seguido da moldagem dos blocos em fôrmas plásticas (Figura 2) e adensamento em mesa vibratória. A relação água/cimento $(0,8)$ proporcionou para todos os traços uma adequada trabalhabilidade das misturas e a vibração mecânica das misturas possibilitou a adequada moldagem das peças. Após desmoldados, os blocos permaneceram numa câmara úmida em processo de cura por um período de 28 dias.

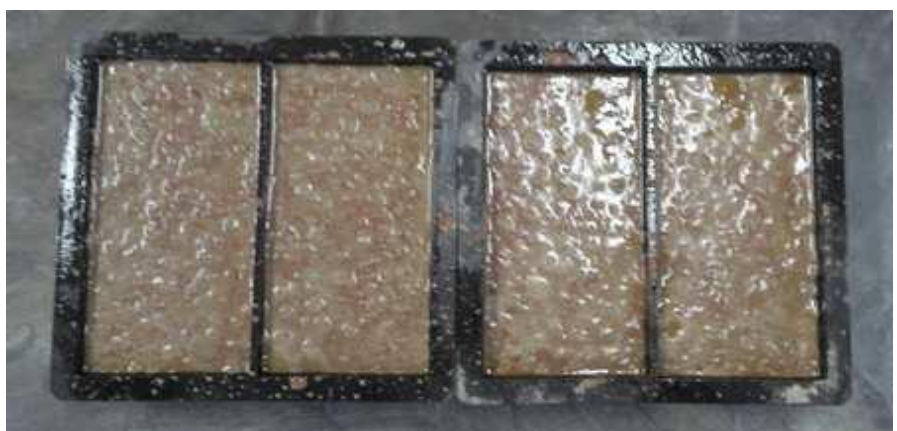

Figura 2: Moldagem dos blocos com concreto convencional e com concreto contendo agregados cerâmicos.

\subsection{Resistência à compressão}

Para obtenção da resistência à compressão dos tijolos maciços cerâmicos foram produzidos corpos de prova (Figura 3A) em conformidade com a ABNT NBR 15270-2:2017 [16], com procedimentos de união e capeamento das partes com pasta de cimento. Para os blocos de concreto com agregados cerâmicos (Figura 3C) foram seguidos os procedimentos da ABNT NBR 9781:2013 [9], incluindo-se o capeamento com pasta de cimento de ambas as faces para ajuste dos pratos da máquina durante o ensaio de compressão.
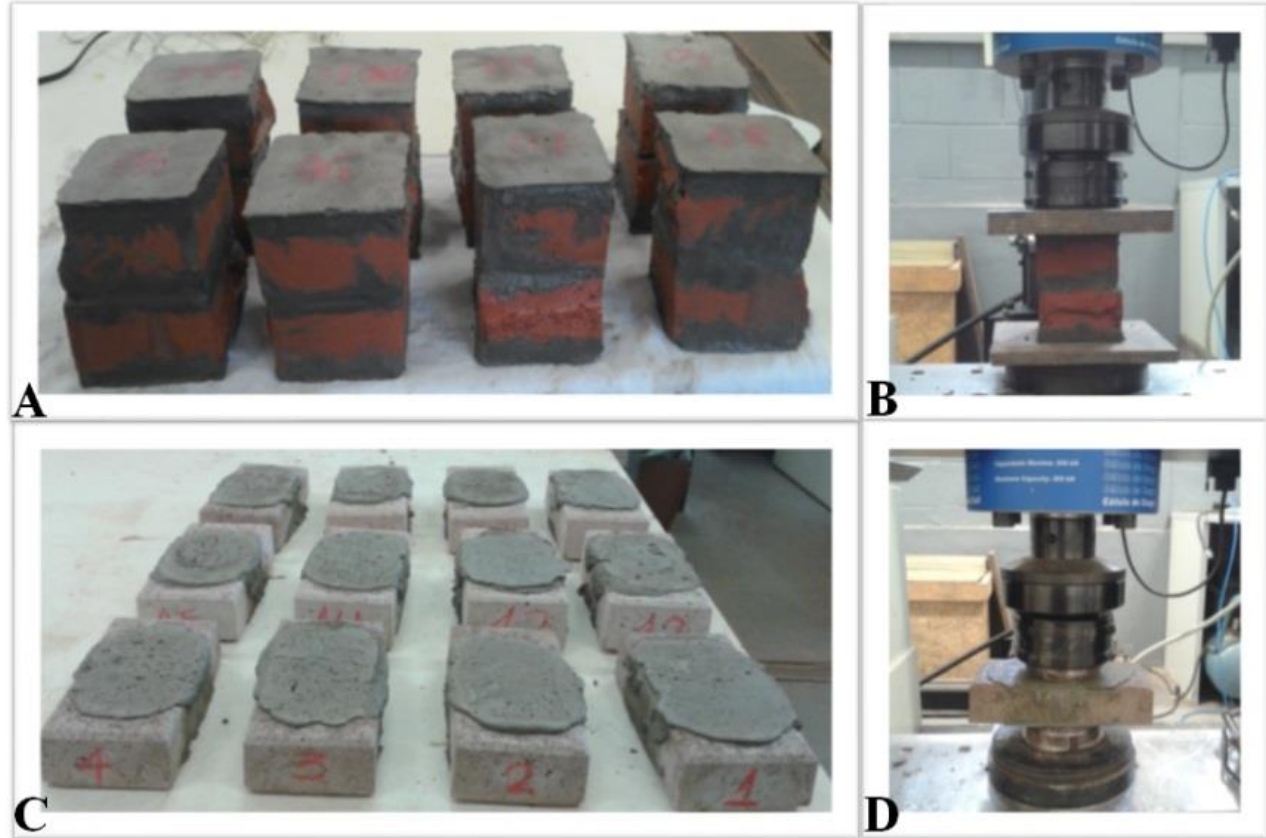

Figura 3: Preparação dos corpos de prova e ensaio à compressão simples. (A) e (B) tijolos maciços cerâmicos; (C) e (D) blocos com agregados cerâmicos. 
Os corpos de prova de tijolos cerâmicos e dos blocos foram submetidos ao processo de saturação por imersão em água por um período de 24 horas, precedendo o ensaio de compressão simples (Figuras 3B e 3D) numa máquina de ensaios universal (EMIC, modelo DL30000, Brasil), com velocidade de carregamento igual a $0,05 \mathrm{MPa} / \mathrm{s}$.

\subsection{Análise da viabilidade econômica}

Pela análise de investimentos tem-se o propósito de avaliar o efeito do capital investido num determinado projeto e mapear os seus resultados futuros. Segundo FERREIRA [18], essa análise é uma técnica que permite avaliar as diferentes alternativas de decisões econômicas e seus resultados, por comparação, para a tomada da melhor decisão, que atenda aos objetivos da empresa, como por exemplo: a substituição de equipamentos, o lançamento de um novo produto, a modernização e/ou aquisição. Adicionalmente, conforme afirmado por MEGLIORINI e VALLIM [19] a análise de investimento é o modo de antecipar, por meio de estimativas, os resultados oferecidos pelos projetos e auxiliar a tomada de decisões. Para HOJI [20] a análise econômica consiste em avaliar o fluxo de caixa e revela resultados financeiros futuros gerados pelo investimento realizado. Esse fluxo de caixa é a projeção de lucro líquido, excluindo-se os itens que não afetam o caixa (depreciação e amortização), comparando com o desembolso em investimentos fixos.

Nesse contexto, um dos principais indicadores utilizados na avaliação econômica de investimentos é o Valor Presente Líquido (VPL) que segundo MEGLIORINI e VALLIM [19] e HOJI [20] representa a diferença entre o valor descontado do fluxo de caixa e o valor do investimento inicial de um projeto. Os projetos de investimento que apresentam VPL maior ou igual a zero devem ser aceitos, pois geram retorno igual ou superior ao custo de capital, contrariamente quando o retorno é inferior ao seu custo de capital, o projeto deixa de ser atrativo.

Outro indicador de viabilidade econômica de um projeto de investimento é a taxa interna de retorno (TIR), utilizada para igualar o valor investido com os saldos finais projetados no caixa. A TIR é a taxa de desconto que torna o valor atual líquido do investimento igual a zero, também chamada de taxa interna efetiva de rentabilidade [21]. Para ASSAF NETO [22] a TIR representa a rentabilidade do projeto expressa em termos de taxa de juros compostos e deve ser comparada com a taxa mínima de atratividade (TMA), para aceitação ou não do projeto. Para a análise de viabilidade econômica foi utilizada uma TMA de 15\% ao ano, levando-se em conta as condições do setor da construção civil na economia brasileira.

\section{RESULTADOS}

A análise de materiais para serem utilizados em processos de reuso, além da escolha daqueles que sejam adequados sob a ótica de tecnologias existentes ou em desenvolvimento para o cumprimento das especificações técnicas, também determina a potencialização e agregação de valor ao material reaproveitado.

\subsection{Viabilidade técnica e destinação dos blocos}

O ensaio de compressão simples dos tijolos maciços cerâmicos apresentou como resultado a resistência média de 9,26 MPa (Figura 4). Tendo em vista que a ABNT NBR 15270-1:2017 [23] especifica para tijolos cerâmicos maciços de vedação a resistência mínima de compressão $\left(\mathrm{f}_{\mathrm{b}}\right)$ igual à 4,0 $\mathrm{MPa}$ (classe VED 40) e para fins estruturais cinco classes (EST60 = 6,0 MPa; EST80 = 8,0 MPa; EST100 = 10,0 MPa; EST120 = 12,0 $\mathrm{MPa}$ e EST140 = 14,0 MPa), verificou-se que os tijolos ensaiados apresentaram resistência à compressão com indicativo para vedação, bem como para uso estrutural até a classe de resistência EST80. 


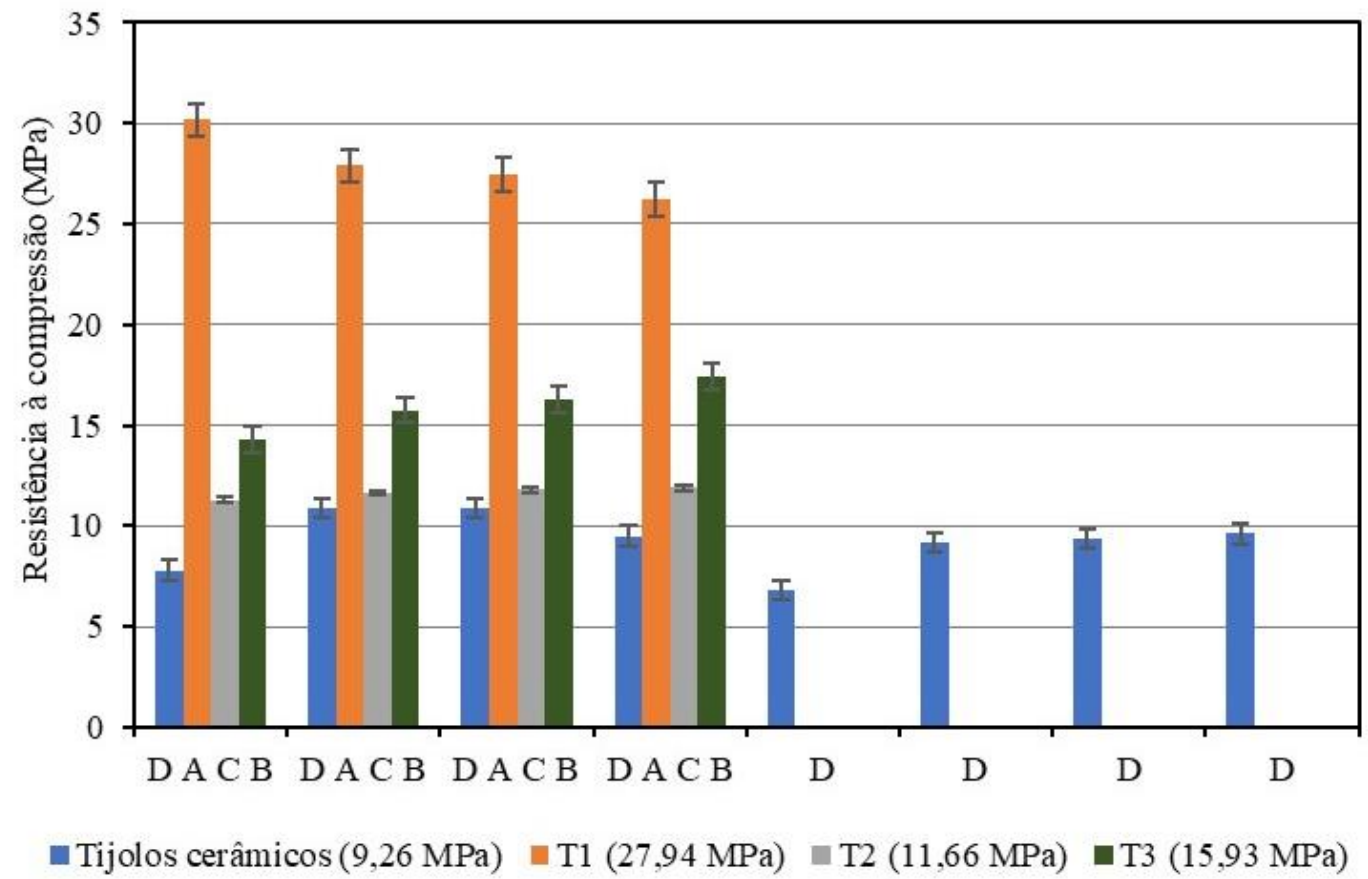

Figura 4: Resistência à compressão simples aos 28 dias e agrupamento pelo Método de Tukey, com margem de erro de $5,0 \%$. Letras distintas implicam em diferenças estatísticas.

Os três traços de concreto elaborados com resíduo de tijolo cerâmico moído, de forma comparativa (Figura 4), proporcionaram blocos com resistências à compressão distintas e superior àquela obtida dos tijolos maciços cerâmicos, com aumento de resistência da ordem de $201,7 \% ; 25,9 \%$ e $72,0 \%$, para os traços T1 (resistência média igual a 27,94 MPa), T2 (resistência média igual a 11,66 MPa) e T3 (resistência média igual a 15,93 MPa), respectivamente. Nesse aspecto, os produtos gerados apresentam vantagens em relação aos tijolos maciços cerâmicos.

Comparando-se os resultados da resistência a compressão dos blocos com traços elaborados com a incorporação do tijolo reciclado e corroborando com CABRAL et al. [17], a substituição parcial dos agregados graúdo e miúdo natural por agregados de tijolos triturados implicou na redução da resistência em relação aos traços T1 e T3, nos quais as substituições se deram exclusivamente para os agregados miúdos. A substituição do agregado natural produz redução da resistência, no entanto esse efeito se intensificou no traço T2 pela substituição do agregado graúdo.

A análise estatística dos resultados, com o teste de Tukey a 95\% de confiança (Figura 4), mostra que a resistência à compressão apresentou médias com diferenças significativas entre os grupos dos blocos de concreto, sendo, portanto, influenciada pelo percentual de agregado cerâmico utilizado na substituição dos agregados convencionais. O traço T1, com substituição parcial apenas do agregado graúdo, possibilitou resistência muito superior às demais (Figura 4). No caso do traço T2, que apresentou a menor resistência (11,66 $\mathrm{MPa}$ ), tem-se a vantagem de uma maior inserção dos resíduos cerâmicos, possibilitando o uso de duas faixas granulométricas (graúdo e miúda), cujo emprego pode ser favorável do ponto de vista de dar destino aos resíduos cerâmicos.

\subsection{Viabilidade econômica dos blocos}

Considerado que a produção média da olaria é de 100.000 tijolos por mês e que $10 \%$ dessa produção apresenta algum tipo de defeito (quebras, fendas, empenamento), resulta anualmente numa quantidade de 1.200.000 tijolos produzidos e 120.000 tijolos descartados. Com base nessas considerações, os tijolos descartados correspondem a uma quantidade aproximada de 300 toneladas por ano. Neste projeto foram utilizados 20 tijolos fragmentados em moinho de martelos, resultando em aproximadamente $50 \mathrm{~kg}$ de resíduo de tijolo moído, a fim de confeccionar os blocos.

Se todo o resíduo gerado for moído e destinado a fabricação de blocos, a empresa tem disponível um total de 300 toneladas/ano do agregado miúdo. Com base na composição do traço T1, para o qual na fabricação de quatro (4) blocos consumiu-se um (1) kg de cimento e na quantidade de resíduos miúdos gerados ao 
ano como substituto de $80 \%$ da massa de areia, serão produzidos anualmente 400.000 blocos, sendo necessárias 100 ton de cimento, 60 ton de areia e 200 ton de brita.

$\mathrm{O}$ investimento inicial considerado na implantação do projeto foi uma máquina para fabricação de blocos de concreto, uma betoneira e uma mesa vibratória. O valor desses equipamentos foi de R $\$ 111.776,00$, com um valor residual de $\mathrm{R} \$ 11.177,60$ e uma vida útil de 15 anos. Esse foi o único investimento necessário para a geração do novo produto, visto que o processo está diretamente ligado às atividades da olaria. Portanto, o investimento referente à britadeira e seus custos de operação, assim como os custos relativos à cura dos blocos estão inclusos na análise porque já fazem parte dos custos correntes da empresa.

Os custos anuais (Tabela 2), considerando a não incorporação dos resíduos na produção dos blocos podem ser confrontados com os custos considerando-se o aproveitamento dos resíduos (agregados reciclados), o que impacta numa redução anual de $\mathrm{R} \$ 45.102,04$. O orçamento dos materiais tem por base os preços que a olaria paga pelas matérias primas para a produção de artefatos sem os agregados reciclados.

Tabela 2: Custo anual para produção de 400 mil blocos, sem e com a utilização de agregados cerâmicos reciclados.

\begin{tabular}{l|l|l}
\hline DESCRIÇÃO & $\begin{array}{l}\text { SEM AGREGADOS RECICLADOS } \\
(\mathbf{R} \$)\end{array}$ & $\begin{array}{l}\text { COM AGREGADOS RECICLADOS } \\
(\mathbf{R} \$ \mathbf{)}\end{array}$ \\
\hline Mão de obra & $143.133,90$ & $143.133,90$ \\
\hline Despesas gerais & $49.200,00$ & $49.200,00$ \\
\hline Materiais & $79.102,04$ & $64.000,00$ \\
\hline Descarte & $30.000,00$ & 0,00 \\
\hline Depreciação & $6.706,56$ & $6.706,56$ \\
\hline Total & $308.142,50$ & $263.040,46$ \\
\hline
\end{tabular}

Para o cálculo das receitas provenientes da venda do novo produto foi considerada uma produção conforme a quantidade de resíduos disponíveis resultando blocos do tipo 'paver' com largura igual a $100 \mathrm{~mm}$, comprimento igual a $200 \mathrm{~mm}$ e $60 \mathrm{~mm}$ de espessura.

\section{DISCUSSÃO}

\subsection{Viabilidade técnica e destinação dos blocos}

Os empregos dos traços com substituição dos agregados convencionais proporcionaram resultados mais homogêneos (Figura 4), tendo em vista que os respectivos valores dos coeficientes de variação $\left(\operatorname{CoVar}_{\mathrm{T} 1}=\right.$ $\left.5,90 \% ; \operatorname{CoVar}_{\mathrm{T} 2}=2,36 \% ; \mathrm{CoVar}_{\mathrm{T} 3}=8,29 \%\right)$ resultaram menores que aquele obtido para os tijolos maciços cerâmicos $\left(\operatorname{CoVar}_{\text {Tijolos }}=15,09 \%\right)$. Nesse contexto, SOARES [24] afirmou que podem ser considerados dados homogêneos aqueles que apresentam valores de coeficiente de variação menores que $25 \%$.

Nos traços elaborados com agregados da reciclagem do concreto e da reciclagem de tijolos de argila, na pesquisa desenvolvida por POON e CHAN [7], o emprego dos agregados oriundos da trituração de tijolos em substituição àqueles de concreto, nas razões de $25 \%, 50 \%$ e $75 \%$, produziram substancial diminuição na resistência à compressão de blocos para pavimentação, levando a restrições desses para uso de tráfego e de pedestres.

No aspecto de emprego de blocos maciços de concreto dosados com agregados convencionais (naturais ou artificiais), para pavimentações de vias com tráfego de veículos comerciais de linha, em conformidade com a ABNT NBR 9781:2013 [9] é requerida a resistência mínima à compressão de $35 \mathrm{MPa}$. Entretanto, FIORITI [25] sugeriu que blocos de concreto produzidos com traços modificados pela substituição de agregados e com resistência à compressão da ordem de $15 \mathrm{MPa}$, podem ser empregados para pavimentação de praças, calçadas e outros locais com trânsito leve. Nesse aspecto, HOOD [6] afirmou que para situações específicas de menor solicitação de tráfego de veículos ou de trânsito de pedestres, é comum o uso de blocos com resistência a compressão na faixa de $25 \mathrm{MPa}$. Consequentemente, o traço T1 (Figura 4), com substituição parcial do agregado graúdo, proporcionou blocos com resistência à compressão apropriada para as aplicações sugeridas por esses autores.

No que concerne às aplicações dos blocos para alvenarias, verificou-se pelas resistências à compressão que todos os blocos produzidos para esta pesquisa (Figura 4) podem ser empregados como elemento de vedação, uma vez que todos os traços superaram a resistência mínima da classe VED 40 (ABNT NBR 
15270-1:2017 [23]). Os blocos produzidos com os traços modificados (Figura 4) apresentaram resistências $\left(\mathrm{f}_{\mathrm{b}}\right)$ que viabilizam suas aplicações para fins estruturais, sendo o traço T2 limitado à classe EST100 e os traços T1 e T3 enquadrados na classe EST140.

\subsection{Viabilidade econômica dos blocos de concreto}

Foram considerados três cenários para o cálculo da viabilidade econômica (Tabela 3). No primeiro cenário adotou-se a produção equivalente a 400.000 blocos de concreto sem qualquer substituição dos agregados convencionais; no segundo cenário, considerou-se a mesma produção, porém, com a utilização do traço T3 (substituição de $100 \%$ do agregado miúdo natural por agregado cerâmico reciclado RTM $^{2}$ ).

Tabela 3: Rendimento e receita da produção anual dos blocos 'pavers' nos três cenários analisados.

\begin{tabular}{l|l|l|l|l}
\hline CENÁRIO & $\begin{array}{l}\text { QUANTIDADE PRODUZIDA } \\
\text { (BLOCOS/ANO) }\end{array}$ & $\begin{array}{l}\text { RENDIMENTO* } \\
\mathbf{( m}^{\mathbf{2}}\end{array}$ & $\begin{array}{l}\text { PREÇO } \\
\left(\mathbf{R} \mathbf{\$} \mathbf{m}^{2}\right)\end{array}$ & $\begin{array}{l}\text { RECEITA ANUAL } \\
(\mathbf{R} \$ \mathbf{)}\end{array}$ \\
\hline $\mathbf{1}$ & 400.000 & 8.000 & 40,00 & $320.000,00$ \\
\hline $\mathbf{2}$ & 400.000 & 8.000 & 35,00 & $280.000,00$ \\
\hline $\mathbf{3}$ & 480.000 & 9.600 & 35,00 & $336.000,00$ \\
\hline
\end{tabular}

* Consumo de 50 unidades $/ \mathrm{m}^{2}$.

Para o terceiro cenário, considerou-se a produção de 480.000 blocos com a utilização do traço T1 (substituição de $80 \%$ do agregado miúdo natural por agregado cerâmico reciclado $\mathrm{RTM}^{2}$ ). Tendo por base as dimensões (largura e comprimento) dos blocos produzidos para atender cada unidade de área $\left(\mathrm{m}^{2}\right)$ são necessárias 50 unidades.

$\mathrm{Na}$ análise do primeiro cenário (Tabela 4) os custos representam 96,3\% da receita e o resultado anual é insuficiente para cobrir o investimento inicial nos cinco anos de horizonte do projeto. Ainda, considerando o nível de produção de 400 mil blocos ao ano, em termos nominais seria necessário um período de pelo menos dez anos para recuperar o investimento inicial.

Tabela 4: Fluxo de caixa sem substituição de agregados convencionais e produção de 400 mil blocos ao ano.

\begin{tabular}{|c|c|c|c|c|c|c|}
\hline \multirow{2}{*}{ ITEM } & \multicolumn{6}{|c|}{ TEMPO (ANOS) } \\
\hline & 0 & 1 & 2 & 3 & 4 & 5 \\
\hline Investimento (R\$) & $-111.776,00$ & & & & & \\
\hline Receitas (R\$) & & $320.000,00$ & $320.000,00$ & $320.000,00$ & $320.000,00$ & $320.000,00$ \\
\hline Custos (R\$) & & $308.142,50$ & $308.142,50$ & $308.142,50$ & $308.142,50$ & $308.142,50$ \\
\hline Fluxo de caixa $(R \$)$ & $-111.776,00$ & $11.857,50$ & $11.857,50$ & $11.857,50$ & $11.857,50$ & $11.857,50$ \\
\hline VPL (R\$) & \multicolumn{6}{|l|}{$-62.632,89$} \\
\hline TIR & \multicolumn{6}{|l|}{$-17,99 \%$} \\
\hline
\end{tabular}

$\mathrm{Na}$ análise do segundo cenário (Tabela 5) os custos representam 93,9\% da receita e, com a total utilização dos resíduos da olaria a recuperação do capital investido seria reduzida para sete anos. No entanto, para um horizonte do projeto de cinco anos, o projeto ainda não apresenta viabilidade econômica devido ao valor presente líquido negativo e a consequente taxa interna de retorno também negativa. 
Tabela 5: Fluxo de caixa com substituição de $100 \%$ da areia por $\mathrm{RTM}^{2}$ e produção de 400 mil blocos ao ano.

\begin{tabular}{|c|c|c|c|c|c|c|}
\hline \multirow{2}{*}{ ITEM } & \multicolumn{6}{|c|}{ TEMPO (ANOS) } \\
\hline & 0 & 1 & 2 & 3 & 4 & 5 \\
\hline Investimento $(\mathbf{R} \$)$ & $-111.776,00$ & & & & & \\
\hline Receitas (R\$) & & $280.000,00$ & $280.000,00$ & $280.000,00$ & $280.000,00$ & $280.000,00$ \\
\hline Custos (R\$) & & $263.040,46$ & $263.040,46$ & $263.040,46$ & $263.040,46$ & $263.040,46$ \\
\hline Fluxo de caixa $(R \$)$ & $-111.776,00$ & $16.959,54$ & $16.959,54$ & $16.959,54$ & $16.959,54$ & $16.959,54$ \\
\hline VPL (R\$) & \multicolumn{6}{|l|}{$-47.760,86$} \\
\hline TIR & \multicolumn{6}{|l|}{$-8,55 \%$} \\
\hline
\end{tabular}

A análise desses dois primeiros cenários indicou a necessidade de definir um novo plano de produção para o projeto. Esse novo plano (Cenário 3, Tabela 6) consistiu em considerar o aumento na produção anual de tijolos e a redução de $20 \%$ no aproveitamento dos resíduos da olaria. Consequentemente, houve aumento das receitas, entretanto, houve também aumento nos custos devido a utilização adicional de $20 \%$ de agregado miúdo natural (areia) no traço para produção dos blocos.

Tabela 6: Fluxo de caixa com substituição de $80 \%$ da areia por $\mathrm{RTM}^{2}$ e produção de 480 mil blocos ao ano (Cenário 3).

\begin{tabular}{|c|c|c|c|c|c|c|}
\hline \multirow[t]{2}{*}{ ITEM } & \multicolumn{6}{|c|}{ TEMPO (ANOS) } \\
\hline & 0 & 1 & 2 & 3 & 4 & 5 \\
\hline Investimento (R\$) & $-111.776,00$ & & & & & \\
\hline Receitas (R\$) & & $336.000,00$ & $336.000,00$ & $336.000,00$ & $336.000,00$ & $336.000,00$ \\
\hline Custos (R\$) & & $278.860,87$ & $278.860,87$ & $278.860,87$ & $278.860,87$ & $278.860,87$ \\
\hline Fluxo de caixa (R\$) & $-111.776,00$ & $57.139,13$ & $57.139,13$ & $57.139,13$ & $57.139,13$ & $57.139,13$ \\
\hline VPL (R\$) & \multicolumn{6}{|l|}{$69.359,33$} \\
\hline TIR & \multicolumn{6}{|l|}{$42,38 \%$} \\
\hline
\end{tabular}

Os resultados apresentados na Tabela 6 mostram que a fabricação de 480 mil blocos ao ano com $80 \%$ de substituição do agregado miúdo por resíduos de olaria é um projeto economicamente viável num horizonte de aplicação de cinco anos. A partir destes resultados e considerando outros cenários com aumento nos custos totais de $5 \%$ ou $8 \%$ mantendo constante a receita, o fluxo de caixa apresenta valores positivos do VPL ( $\mathrm{R} \$ 28.716,52$ e $\mathrm{R} \$ 4.330,81$, respectivamente) com taxas internas de retorno $(26,90 \%$ e $16,87 \%$, respectivamente) superiores a taxa mínima de atratividade de $15 \%$.

O presente estudo demonstrou ser uma solução viável o aproveitamento de resíduos de tijolos cerâmicos, como agregado na modificação do traço $(1: 3: 2: 0,8)$ para produção de blocos de concreto. Os blocos produzidos com a substituição de $80 \%$ do agregado miúdo (traço T1), no que se refere ao requisito da propriedade mecânica de resistência à compressão resultaram aptos para execução de alvenarias de vedação, bem como para alvenarias estruturais (tendo superado a resistência da classe EST140). Esses blocos alcançaram resistências à compressão com as quais, como sugerido por [6,25], poderiam ser empregados para fins de pavimentação de locais com trânsito de pedestres ou de veículos leves.

Para os blocos maciços de concreto a serem utilizados em obras de pavimentação, além do requisito de resistência à compressão, a ABNT NBR 9781:2013 [9] estabelece como facultativa a determinação da resistência à abrasão. Com relação aos requisitos das propriedades físicas, o valor médio da absorção d'água da amostra não deve superar 6\% [9]. No que se refere aos elementos cerâmicos destinados às construções de alvenarias, tanto da classe VED40 quanto para todas as classes estruturais (EST), em conformidade com a ABNT NBR 15270-1:2017 [23], o índice de absorção d'água deve estar compreendido na faixa de 8 a 25\%.

\section{CONCLUSÕES}

Os resultados obtidos nos ensaios preliminares de resistência à compressão simples e na viabilidade econômica indicaram que é possível a substituição de agregados convencionais por agregados reciclados provenientes de resíduos de tijolos cerâmicos. Contudo, levando-se em conta os três cenários de projeto propostos, a melhor alternativa para a utilização dos resíduos de uma olaria é a substituição de $80 \%$ da massa do agregado miúdo natural por agregado reciclado com a mesma granulometria, em mistura cimentícia para fabricação de 
blocos destinados à pavimentação ('pavers') ou, ainda, de blocos para alvenaria. Para esse traço com maior viabilidade econômica (T1), em virtude da resistência alcançada, não há restrições para uso em alvenaria de vedação ou estrutural. Entretanto, conforme sugerido na literatura a aplicação desses blocos para pavimentação está restrita a trânsito de pedestres e veículos leves. Concernente à análise econômica dessa solução, para um horizonte de cinco anos e uma taxa de atratividade de 15\%, a utilização desses resíduos apresentou viabilidade econômica com o aumento das receitas e a diminuição de custos, acrescentando competitividade à indústria de materiais de construção civil.

\section{AGRADECIMENTOS}

À Olaria L.C. de Camargo pela disponibilização dos tijolos e materiais para produção dos blocos. Ao técnico do Laboratório de Materiais e Estruturas da Faculdade de Engenharia Agrícola da Universidade Estadual de Campinas, Eng. Agrícola Paulo Gustavo Krejci Nunes, pelo suporte técnico nos ensaios.

\section{BIBLIOGRAFIA}

[1] COLETTI, C., "Bricktech: Assessment for the use of waste in the brick production. Petrophysical characterization of new mix designs and optimization of the firing conditions", Plinius, v. 42, pp. 20-26, Oct. 2016.

[2] ZHANG, L., "Production of bricks from waste materials - A review", Construction and Building Materials, v. 47, pp. 643-655, Oct. 2013.

[3] OLIVEIRA, O.M., Utilização de resíduos da indústria cerâmica para obtenção de novos produtos cerâmicos, Tese de D.Sc., Escola Politécnica/USP, São Paulo, SP, Brasil, 2016.

[4] PELISSER, F., ZAVARISE, N., LONGO, T.A., et al., "Concrete made with recycled tire rubber: Effect of alkaline activation and silica fume addition”, Journal of Cleaner Production, v. 19, n. 6-7, pp. 757-763, May. 2011.

[5] RODRÍGUEZ, C., PARRA, C., CASADO, G., et al., "The incorporation of construction and demolition wastes as recycled mixed aggregates in non-structural concrete precast pieces", Journal of Cleaner Production, v. 127, pp. 152-161, Jul. 2016.

[6] HOOD, R.S.S., Análise da Viabilidade Técnica da Utilização de Resíduos de Construção e Demolição como Agregado Miúdo Reciclado na Confecção de Blocos de Concreto para Pavimentação, Dissertação de M.Sc., Escola de Engenharia/UFRGS, Porto Alegre, RS, Brasil, 2006.

[7] POON, C.S., CHAN, D., "Paving blocks made with recycled concrete aggregate and crushed clay brick", Construction and Building Materials, v. 20, n. 8, pp. 569-577, Jun. 2006.

[8] THOMAS, C., SETIEN, J.A., POLANCO, P.A., et al., "Durability of recycled aggregate concrete", Construction and Building Materials, v. 40, pp. 1054-1065, Mar. 2013.

[9] ASSOCIAÇÃO BRASILEIRA DE NORMAS TÉCNICAS. NBR 9781: Peças de concreto para pavimentação - Especificação e métodos de ensaio. 21p. Rio de Janeiro, 2013.

[10] PENTEADO, C.S.G., CARVALHO, E.V., LINTZ, R.C.C., "Reusing ceramic tile polishing waste in paving block manufacturing”, Journal of Cleaner Production, v. 112, n. 1, pp. 514-520, Jan. 2016.

[11] SILVA, T.D., PAULA, H.M., SILVA, D., et al., "Uso de granulado de borracha em substituição parcial ao agregado miúdo na produção de tijolos ecológicos”, Revista Matéria, v. 22, n. 4, e-11905, 2017. Disponível em <http://www.scielo.br/scielo.php?script=sci_arttext\&pid=S1517-707620170004004 28\&lng=pt\&nr m=iso>. acesso em 27 dez.2017. Epub 02-Out-2017. http://dx.doi.org/10.1590/s1517-707620170004.0239., Out. 2017.

[12] SILVA, R.V., BRITO, J., DHIR, R.K., "Properties and composition of recycled aggregates from construction and demolition waste suitable for concrete production", Construction and Building Materials, v. 65, pp. 201-217, Aug. 2014.

[13] REZENDE, J.L.P., OLIVEIRA, A.D., Análise econômica e social de projetos florestais, 2 ed., Viçosa, UFV, 2008.

[14] BAUMGÄRTNER, S., QUAAS, M.F., "Ecological-economic viability as a criterion of strong sustainability under uncertainty”, Ecological Economics, v. 68, n. 7, pp. 2008-2020, May. 2009.

[15] ROSS, A.S., WESTERFIELD, R.W., JORDAN, B.D., Princípios de Administração Financeira, 2 ed., São Paulo, Atlas, 2000. 
[16] ASSOCIAÇÃO BRASILEIRA DE NORMAS TÉCNICAS. NBR 15270-2: Componentes cerâmicos Blocos e tijolos para alvenaria. Parte 2: Métodos de ensaios. 29p. Rio de Janeiro, 2017.

[17] CABRAL, A.E.B., et al., "Desempenho de concretos com agregados reciclados de cerâmica vermelha", Cerâmica, v. 55, pp. 448-460, Out/Dez. 2009.

[18] FERREIRA, J.O., Estudo da viabilidade técnico-econômica da produção industrial da aguardente do "licor" de laranja, Dissertação de M.Sc., Faculdade de Ciências Farmacêuticas/UNESP, Araraquara, SP, Brasil, 2005.

[19] MEGLIORINI, E., VALLIM, M.A., Administração financeira: uma abordagem brasileira, $1^{\text {a }}$.ed., São Paulo, Pearson Prentice Hall, 2009.

[20] HOJI, M., Administração financeira e orçamentária, 9 ed., São Paulo, Atlas, 2010.

[21] REBELATTO, D., Projeto de Investimento, 1 ed., Barueri, Manole, 2004.

[22] ASSAF NETO, A., Estrutura e análise de balanços: um enfoque econômico-financeiro, 10 ed., São Paulo, Atlas, 2012.

[23] ASSOCIAÇÃO BRASILEIRA DE NORMAS TÉCNICAS. NBR 15270-1: Componentes cerâmicos Blocos e tijolos para alvenaria. Parte 1: Requisitos. 26p. Rio de Janeiro, 2017.

[24] SOARES, J.F., SIQUEIRA, A.L., Introdução à estatística médica, 2 ed., Belo Horizonte, Coopmed, 2002.

[25] FIORITI, C.F., Pavimentos intertravados de concreto utilizando resíduos de pneus como material alternativo, Tese de D.Sc., EESC/USP, São Carlos, SP, Brasil, 2007. 